\title{
An Interactive e-Book Design and its Development to Enhance the Literacy Learning of the Minority Language Students
}

\author{
Muneeroh Phadung \\ Computer Education Program, Faculty of Science Technology and Agriculture, \\ Yala Rajabhat University \\ Yala, Thailand
}

\begin{abstract}
An interactive multimedia application as e-books has benefits and capabilities for enhancing learning rates and increasing students' concentration and involvement in the learning activities. This study presents interactive e-book design areas to support literacy learning for minority language students within the primary school level. There are three main components of design framework including multimedia design, interactive design, and learning design. Moreover, the researcher attempts to design all three components based on the cultural theme to help minority language students reflect their own cultures and begin to understand the cultures of the language that they are learning. The prototype consists of two main modules: manual module and automatic module. Furthermore, the researcher would like students to interact with the program through interactive whiteboard as a cooperative tool in the classroom. The interactive e-book is expected to be an alternative educational tool to solve the learning problems of minority language students.
\end{abstract}

\section{Introduction}

Ethnic identity of minorities is a significant topic in many fields of research e.g., sociology, education, psychology and others [1]. Minority groups have been defined as groups with different ethnic backgrounds, cultural traditions, religious or linguistic characteristics from the majority of the population [2]; [3]. UNESCO claims that minorities are one of the most disadvantageous groups and has realized the educational problems of minority children. Therefore, UNESCO, as a part of "Education for All Goals" in the Dakar Forum, has aimed to develop strategies to enhance the quality of compulsory primary education [4].

Recently, several studies have made claims concerning the educational problems of minority children in many countries [5], [6], [7], [8]. In the United States, a report by the National Literacy Panel on Language-Minority Children and Youth in 2006 points out that there is a growing number of students coming from countries where English is not the primary language. These students cannot read and write proficiently in English and cannot participate fully in American schools [5].

In Thailand, Yala et al. are three southern border provinces that have cultural identities different from the other parts of the country. In everyday life, 83 percent of the people in this area use the Pattani Malay language [9]. This language is one of the dialects influenced by the Malaysian language [10]. However, the official language used in schools is still Thai. Consequently, because of their poor ability in using Thai language, these minority language students face numerous difficulties when it comes to learning the content taught in schools. The academic report founded that children's learning achievement is below the Thai standard level and, most importantly, it is the lowest score in the country. Besides this, the teaching methods are not compatible with their way of life and traditions, which exacerbates the educational problems [11].

Several types of computer software are widely used by students both at home and in school [12]. Multimedia software, especially interactive e-books, can be powerful educational tools for promoting students' literacy and language learning outcomes [13]. However, some e-books on the market are not efficient for language learning. Therefore, educators must be careful when using them [12].

Furthermore, e-books and storytelling can be used to improve children's listening, speaking, writing, and reading skills [14]. Storytelling is useful for emotional and social skills, which can foster a good relationship not only among children but also between adults and children [15]. In addition, the growth of computer technology has had a significant effect on the language learning. Computer software is widely used for children both at home and school [12]. Multimedia software, especially interactive storybooks, can be useful instructional tools for fostering children's literacy and language learning [16], [17], [18], [19]. However, some e-books on the market are still not efficient for literacy development which implies that 
educators must be careful when using electronic products [12]

Roskos et al. [17] directed their research towards understanding how expertise is acquired, how to design e-books for supporting literacy learning, and how to evaluate e-books as material resources in literacy teaching and learning. Similarly, De Jong \& Bus [20] and Phadung et al. [8] suggested how well to design suited e-books are in supporting literacy.

With this theoretical basis as a guide of the study, that could be applied for using interactive e-books in the classroom and also be a powerful tool to effectively teach ethnic minority children and improve their literacy learning achievement.

Accordingly, educators need to provide the alternative educational tools to solve the learning problems of students in ethnic minority communities. Using interesting materials at all levels of education including primary education, these students can learn the official language as a second language more effectively with good attitudes towards learning. The potential and advantage of multimedia application in language learning have inspired the researcher to realize that using an interactive e-book can support literacy learning and second language learning for minority language students. The key to this success is that students will be motivated to learn a language through the use of interesting tools.

\section{Objectives and Scopes}

\subsection{The interactive e-book objectives}

The objectives of the interactive e-book development are:

- To set the interactive e-book design framework for minority language students.

- To develop an interactive e-book prototype for minority language students.

- To evaluate informally the satisfaction of the interactive e-book prototype with students and teachers who were the targeted users.

\subsection{The interactive e-book scopes}

The interactive e-book content covered Thai language learning and was based on the current Thai Basic Education Core Curriculum B.E. 2551 (A.D. 2008). The courseware was delivered in Thai. The targeted users were third grade minority language students from three southern border provinces of Thailand using Malay dialect as a mother tongue. This study focuses on the interactive e-book as a cooperative tool in the classroom by using interactive whiteboard. This technique also could be used for individual learning as well.

\section{Interactive E-Book Design Principle}

In order to properly meet the needs and expectations of minority language students, the interactive e-book should reflect good internal designs that encourage literacy learning and facilitate active learning; therefore, the design principles are collected based on reliable literature reviews.

In addition, the interactive e-book design principle was applied using the learning objects design framework [21]. According to the design framework described, a design principle is composed of three significant categories of design:

\section{- Multimedia design}

How components are presented or shown. This design category addresses the composition of visual consistency (e.g., image, animation, video, and text) and sound suitability.

\section{- Interactive design}

How components describe its use for promoting students engagement and increasing students outcomes. This design category addresses the interactivities between the e-book and user that offer an easy-to-use approach, such as providing interactivities suitable for motor skills students.

\section{- Learning design}

How components relate to an instructional objective. The learning design category adopts the guidelines of instruction to foster the students' learning. The researcher is concerned about applying the principles of brain-based learning to this domain for teaching methods and lesson designs. Brain-based learning is motivated that learning can be accelerated and improved if teachers base how and what they teach on the language learning.

Furthermore, the researcher realizes that the cultural theme is also significant because it reflects a home-school connection. This especially helps minority language students reflect their own cultures and understand cultures of the second language that they are learning [22], [23], [24], [25]. The interactive e-book built on a cultural theme can support students' learning. First, it helps students improve the critical thinking and problem-solving skills. Second, choosing topics that mirror the home-school connection and reflect children's own cultures foster their engagement and adoption of the learning skills which, in turn, deepens their thinking [26]. There are an increasing number of bilingual or multilingual children's e-books being produced. These e-books can be used to encourage the diversity and inspire the understanding of both their own cultures and other cultures and traditions. This approach can provide alternative opportunities for minority language students to experience and engage in literature [27] (see Figure $1)$. 


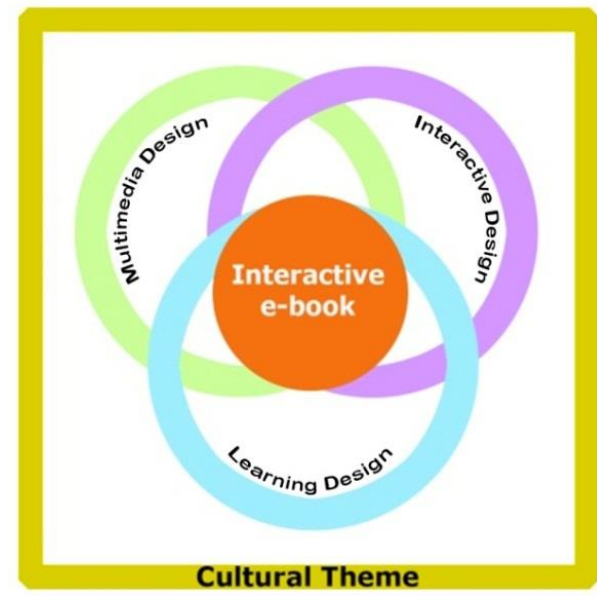

Figure 1. Interactive e-book design framework

\section{Prototype Development}

The interactive e-book "Mana Manee" was an offline application. The content was based on Thai cultural, children's cultural background and the current Thai basic education core curriculum B.E. 2551 (A.D. 2008). This e-book has six chapters. The main characters, "Mana" and "Manee" are role models of oral language learning for children and stimulate learning through real situations. The standard of interactive e-book design will be checked by experts who specialize in multimedia design and Thai language teaching in the further study.

The prototype developed was based on the design framework in Figure 1. The prototype was divided into two main modules including:

\section{- The manual module}

This module has two modes; the first mode is named "Read to Me". At first in the each page, the animation and the narration sound associated with each highlighted sentence appears automatically on the screen. After that, a user can navigate and control the story by clicking buttons on the right top of the screen; the user can repeat this function by clicking the repeat button or clicking on the sentences that the user would like to learn (see Figure 2). The e-book also includes picture-hotspots that the user can click to play hinted animation. The translate button is an optional function, the user can use this function for supporting story understanding from both the narration sound in a second language and with the mother tongue language.

The second mode is named "Read It Myself". The user can use this mode in case that students want to read the e-book by themselves. Its options are the same as "Read to Me"; only the voice narration is disabled in this mode.

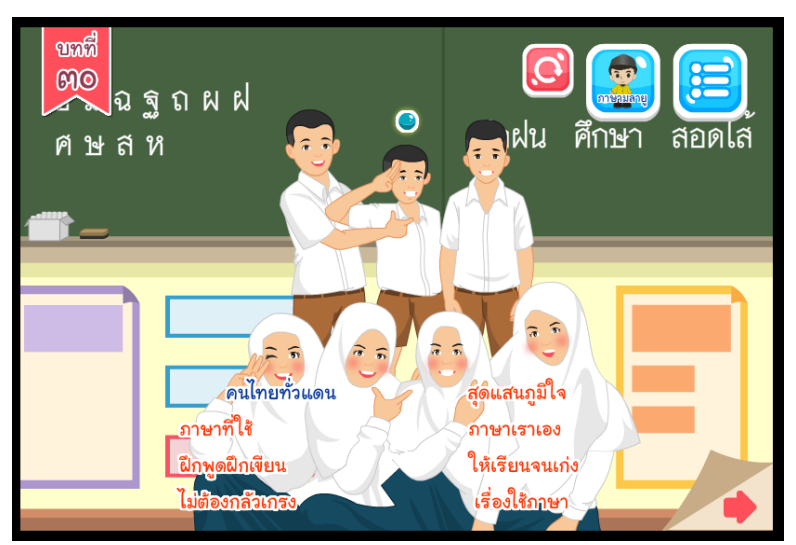

Figure 2. Screenshot of the manual module

- The automatic module

The module is named "AutoPlay". The software allowed the user to play automatically from the first page to the last. The user could control the e-book only using "home", "stop" and "play" buttons (See Figure 3).

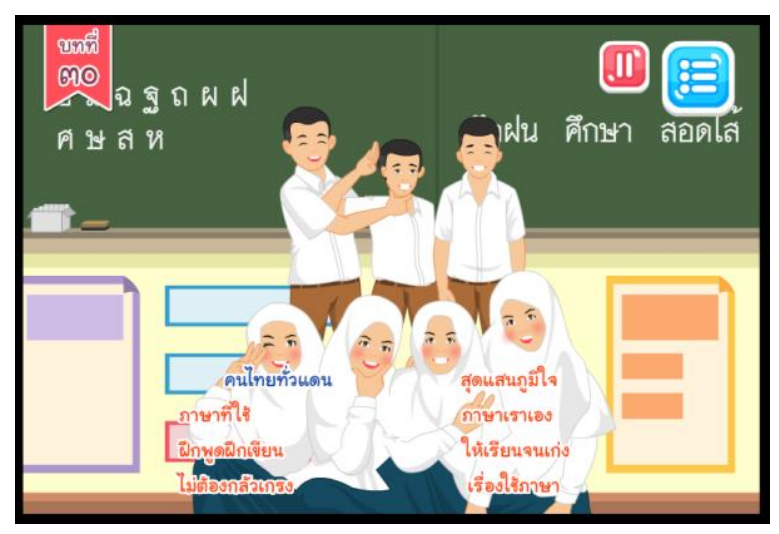

Figure 3. Screenshot of the automatic module

After the development of the prototype, each module has been tested informally with students who were the targeted users and their teachers. From the testing results, they are satisfied with the interactive ebook. The strengths and the weaknesses of the prototype can be improved to fulfill the requirement of the users. Formal assessment for the completed interactive e-book will be conducted soon.

\section{The Interactive E-Book Classroom Environment}

For this study, the interactive e-book was used as a cooperative tool in the classroom by using interactive whiteboard based on Wiimote technology.

Users could interact with the storybook program by using an infrared pointer instead of a mouse. The whiteboard allows users to interact with hotspots and buttons. Users can project a computer onto a whiteboard and control it as a touch screen. The system components (see Figure 4) applied from Johnny Chung Lee's interactive whiteboard system components [28]. 
The teachers and children interact with the interactive e-book program and have navigational capability by giving inputs via infrared pointer. Children experience response from the system on the interactive whiteboard that can enhance their learning motivation and achievement that agree with Cacikova et al. [29].

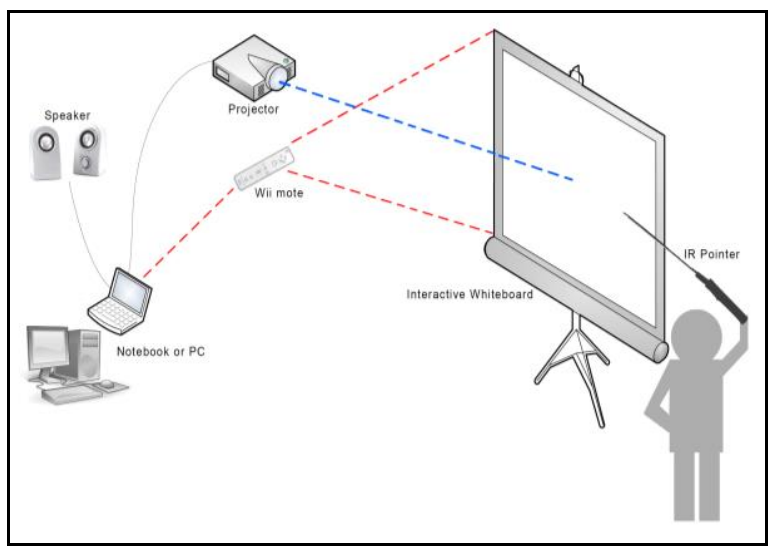

Figure 4. The feature of the interactive e-book classroom environment

\section{Conclusion}

This paper presents usability design strategies in three main areas; multimedia design, interactive design, and learning design. All three main components were designed based on cultural theme. The prototype consists of two main modules including manual module and automatic module. As a cooperative tool, students can interact with the e-book program by using the interactive whiteboard. The interactive e-books can be designed into cooperative tools in the classroom to foster language and literacy learning of minority students. The design framework and the prototype of interactive e-book are only a first step. The researcher realizes that the project is still in the beginning phase of development and will need to be improved in future studies before it can be delivered.

In conclusion, although the technology that focuses on the interactive e-book is not the only solution of children's literacy problems, it is certainly a powerful environment that can be used to motivate and amuse children as they improve their literacy skills and language development.

Expected Outcome and benefits of the Project, these students will have a better chance at becoming bilingual speakers who have the confidence to communicate with others. This will enable students to use their Thai second language as the official language in school.

\section{Acknowledgment}

This work was supported by grants from the National Research Council of Thailand (NRCT) and the Thailand Research Fund (TRF).

\section{References}

[1] Yang, Sh., Li, L., YaLikunjiang, A., Tao, X., Li, Q., \& Gong, S. (2013). Ethnic identity of minority no-fee preservice students. Chinese education and society, 46, 7-89.

[2] Schaefer, R. T. (2012). Racial and Ethnic Groups. Boston, MA: Pearson.

[3] Ahmed, T. (2010). A critical appraisal of EU governance for the protection of minority right. International Journal on Minority and Group Rights, 17 (2), 265-285.

[4] UNESCO. (2000). The Dakar Framework for Action, Office of the Assistant Director-General for Education. Paris: UNESCO.

[5] August, D., \& Shanahan, T. (2006). Executive Summary Developing Literacy in Second-Language Learners: Report of the National Literacy Panel on Language-Minority Children and Youth. New Jersey, London: Lawrence Erlbaum Associates, Inc.

[6] Steensel, R.V. (2006). Relations between sociocultural factors, the home literacy environment and children's literacy development in the first years of primary education. Journal of Research in Reading, 29(4), 367-382.

[7] Fluckiger, B. (2010). Culture-switching in different worlds: Young children's transition experiences. Australasian Journal of Early Childhood, 35(4), 101108.

[8] Phadung, M., Suksakulchai, S., \& Kaewprapan, W. (2012). The design framework of interactive storybook support early literacy learning for ethnic minority children. Proceedings from the World Congress on Engineering and Computer Science conference. San Francisco: CA.

[9] Basic Education Commission (2010), "The evaluation of an applying the bilingual (Thai and Malayu) in teaching and learning project for the Lowest Southern Part of Thailand Report", The teachers' council of Thailand Press, Bangkok, Pp. 5-10.

[10] Isaya, K., Songmuang, J., Sameng A., and Jehdo h. (2010), "Using Jawi alphabets to develop Patani Malay writing system to help preserving and reviving the dialect and local culture: A case study of Tambon Khao Toom, Amphoe Yarang, Pattani province", Journal of Language and Culture, Vol. 29, No. 1, Pp. 35-56.

[11] Kannaovakun, P., Chotikakamthorn, M., Sa-idi, A., Chanhom, R., Paramal, W. and Anakasiri, S. (2010), "Model for the development of bilingual communicative competence of students in the three southern border provinces of Thailand", Songklanakarin Journal of Social Sciences and Humanities, Vol. 16, No. 6, Pp. 933-952.

[12] Korat, O. and Shamir, A. (2006), "How to select CDROM storybooks for young children: The Teacher's Role", The Reading Teacher, Vol. 59, No. 6, Pp. 532543.

[13] Segers, E. and Verhoeven, L. (2002), "Multimedia support of early literacy learning", Computer \& Education, Vol. 32, No. 3, Pp. 207-221.

[14] Goodman, K., Bird, L. B., \& Goodman. (1991). The whole language catalog. Santa Rosa, CA: American School Publishers.

[15] Justice, L. M., \& Pence, K. L. (2005). Scaffolding with Storybooks: A guide for enhancing young' children's language and literacy achievement. Newark, DE: the International Reading Association, Inc.

[16] Verhallen, M. J. A. J., Bus, A. G. and de Jong, M. T. (2006), "The Promise of Multimedia Stories for Kindergarten Children at Risk", Journal of Educational Psychology, Vol. 98, No. 2, Pp. 410-419. 
[17] Roskos, K., Brueck, J. and Widman, S. (2009), "Investigating analytic tools for e-book design in early literacy learning", Journal of Interactive Online Learning, Vol. 8, No. 3, Pp. 218-240.

[18] Moody, A. K. (2010), "Using electronic books in the classroom to enhance emergent literacy skills in young children", Journal of Literacy and Technology, Vol. 11, No. 4, Pp. 22-52.

[19] Roskos, K., Burstein, K., You, B., Brueck, J. and O'Brien, C. (2011), "A Formative Study of an E-book Instructional Model in Early Literacy", Creative Education, Vol. 2, No. 1, Pp. 10-17.

[20] De Jong, M.T. and Bus, A.G. (2003), "How wellsuited are electronic books to supporting literacy?", Journal of Early Childhood Literacy, Vol. 3, No. 2, Pp. 147-164.

[21] Roskos, K., \& Brueck J. (2009), "The eBook as a learning object in an online world",In Bus, A.G. \& Neuman, S.B. (Eds.), Multimedia and literacy development, Routledge, New York, Pp. 77-88.

[22] Steensel, R.V. (2006), "Relations between sociocultural factors, the home literacy environment and children's literacy development in the first years of primary education", Journal of Research in Reading, Vol. 29, No. 4, Pp. 367-382.

[23] Fluckiger, B. (2010), "Culture-switching in different worlds: Young children's transition experiences", Australasian Journal of Early Childhood, Vol. 35, No. 4, Pp. 101-108.

[24] Korat, O. (2001), "Cultural pedagogy and bridges to literacy: Home and kindergarten", Early Childhood Education Journal, Vol. 28, No. 4, Pp. 225-230.

[25] Schwarzer, D. (2001), "Whole language in a foreign language class: From theory to practice", Foreign Language Annals, Vol. 34, No. 1, Pp. 52-59.

[26] Dubosarsky M., Murphy B., Roehrig G., C. Frost L., Jones J., P. Carlson S., Londo N., S.B. Melchert C., Gettel C., and Bement J. (2011), "Incorporating Cultural Themes to Promote Preschoolers' Critical Thinking in American Indian Head Start Classrooms", Young Children, Vol. 66, No. 5, Pp. 20-29.

[27] Fellowes, J. \& Oakley, G. (2010), "Language literacy and early childhood education", Oxford University Press, Victoria, Pp. 3-26.

[28] Lee, J. Ch. (2013, January 9), "Wii Remote Projects", URL:http://johnnylee.net/projects/wii/

[29] Cacikova, M., Londakova, D., Podhradsky P., \& Londak, J. (2010). Application of multimedia technologies in pre-school and elementary school language education. Proceedings from International conference "ICT for Langauge Learning" 3rd edition. Florence. 